\title{
Development of Peptide Targeted PLGA-PEGylated Nanoparticles Loading Licochalcone-A for Ocular Inflammation
}

\author{
Ruth Galindo ${ }^{1,2, \dagger}$, Elena Sánchez-López ${ }^{1,2,3,4, *,+}$, María José Gómara ${ }^{2}$, Marta Espina ${ }^{1,3} \oplus$, Miren Ettcheto ${ }^{4,5} \oplus^{\circ}$, \\ Amanda Cano ${ }^{1,3,4} \mathbb{0}$, Isabel Haro ${ }^{2} \mathbb{D}$, Antoni Camins ${ }^{4,5,+} \mathbb{D}$ and María Luisa García ${ }^{1,3,4, \dagger}$
}

Citation: Galindo, R.; Sánchez-López,

E.; Gómara, M.J.; Espina, M.;

Ettcheto, M.; Cano, A.; Haro, I.;

Camins, A.; García, M.L.

Development of Peptide Targeted

PLGA-PEGylated Nanoparticles

Loading Licochalcone-A for Ocular

Inflammation. Pharmaceutics 2022, 14,

285. https://doi.org/10.3390/

pharmaceutics14020285

Academic Editor:

Uday B. Kompella

Received: 23 December 2021

Accepted: 20 January 2022

Published: 26 January 2022

Publisher's Note: MDPI stays neutral with regard to jurisdictional claims in published maps and institutional affiliations.

Copyright: (C) 2022 by the authors. Licensee MDPI, Basel, Switzerland. This article is an open access article distributed under the terms and conditions of the Creative Commons Attribution (CC BY) license (https:// creativecommons.org/licenses/by/ $4.0 /)$.
1 Department of Pharmacy, Pharmaceutical Technology and Physical Chemistry, Faculty of Pharmacy and Food Sciences, University of Barcelona, 08028 Barcelona, Spain; ruth.galindo@ub.edu (R.G.); m.espina@ub.edu (M.E.); acanofernandez@ub.edu (A.C.); marisagarcia@ub.edu (M.L.G.)

2 Unit of Synthesis and Biomedical Applications of Peptides, IQAC-CSIC, 08034 Barcelona, Spain; mjgqpp@cid.csic.es (M.J.G.); isabel.haro@iqac.csic.es (I.H.)

3 Institute of Nanoscience and Nanotechnology (IN2UB), University of Barcelona, 08028 Barcelona, Spain

4 Biomedical Research Networking Centre in Neurodegenerative Diseases (CIBERNED), 28031 Madrid, Spain; mirenettcheto@ub.edu (M.E.); camins@ub.edu (A.C.)

5 Department of Pharmacology and Therapeutic Chemistry, Faculty of Pharmacy, University of Barcelona, 08028 Barcelona, Spain

* Correspondence: esanchezlopez@ub.edu

+ These authors contribute equally to this work.

\begin{abstract}
Licochalcone-A is a natural compound with anti-inflammatory properties. However, it possesses low water solubility, making its application for the treatment of ocular inflammation difficult. To overcome this drawback, biodegradable nanoparticles incorporating Licochalcone-A have been developed. Additionally, to avoid fast clearance and increase cellular internalization into the ocular tissues, PLGA nanoparticles have been functionalized using PEG and cell penetrating peptides (Tet-1 and B6). To optimize the formulations, a factorial design was carried out and short-term stability of the nanoparticles was studied. Moreover, morphology was also observed by transmission electron microcopy and in vitro drug release was carried out. Ocular tolerance of the formulations was ensured in vitro and in vivo and anti-inflammatory therapeutic efficacy was also assessed. Surface functionalized nanoparticles loading Licochalcone-A were developed with an average size below $200 \mathrm{~nm}$, a positive surface charge, and a monodisperse population. The formulations were non-irritant and showed a prolonged Licochalcone-A release. Despite the fact that both Licochalcone-A Tet-1 and B6 functionalized nanoparticles demonstrated to be suitable for the treatment of ocular inflammation, B6 targeted nanoparticles provided greater therapeutic efficacy in in vivo assays.
\end{abstract}

Keywords: Licochalcone-A; nanoparticles; ocular inflammation; cell-penetrating peptides; PLGA

\section{Introduction}

One of the most prevalent conditions in ophthalmology is ocular inflammation. This inflammation constitutes the local response of ocular tissues and annexes against an external or internal insult. Moreover, this process may be able to produce irreversible damage to the ocular function [1]. The inflammation process triggers the production of growth factors and cytokines and stimulates the enzyme phospholipase A2 (PLA2), which leads to the synthesis of eicosanoids from a phospholipid found in cell membranes, arachidonic acid (AA). AA can stimulate the production of pro-inflammatory cytokines and initiate apoptosis. Moreover, AA-derived eicosanoids regulate immunopathological and inflammatory processes through different physiological responses, vascular homeostasis, and platelet aggregation [2].

For the treatment of ocular inflammation, non-steroidal anti-inflammatory drugs as well as corticoids are currently used. However, both cause several adverse effects [3]. In 
this area, research on novel approaches avoiding side effects constitutes an unmet medical need. In this sense, Licochalcone-A (Lico-A) is a characteristic chalcone isolated from the root of Glycyrrhiza inflata, which has been used in traditional medicine to treat various disorders such as gastric ulcer, bronchial asthma, and inflammation [4]. The biological properties of Lico-A include antiparasitic, antiproliferative, antitumoral, antimicrobial, antiviral, osteogenic, immunomodulatory, and anti-inflammatory activities [5,6]. Moreover, Lico-A exhibits a carrageenan-induced anti-inflammatory effect in a murine model [6]. Despite the suitable properties of Lico-A against ocular inflammation, its solubility in water is extremely low, making its topical administration as conventional eye-drops difficult $[7,8]$. Moreover, it has also been reported that less than $5 \%$ of conventional ocular formulations are able reach inner ocular tissues [9].

In order to overcome these problems, nanotechnological drug delivery constitutes a suitable approach for active compounds encapsulation and their delivery into target sites [10-12]. Controlled administration of drugs, specially at the ocular level, can offer enormous benefits, including maximizing drug efficacy, minimizing side effects, and improving patient compliance $[13,14]$.

Nanocarriers, such as nanoparticles (NPs), with sizes ranging between 10 and $1000 \mathrm{~nm}$ are of particular interest as drug delivery platforms for treating ocular diseases [15]. Among several carriers, biodegradable polymeric nanoparticles provide several advantages, such as protect the drug from inactivation by enzymes present in the tear film or corneal epithelium, facilitate transcorneal penetration, prolong its stability in the precorneal area, and avoid adverse effects in other organs [1]. Among them, biodegradable polymers such as poly (lactic-co-glycolic acid) (PLGA) have been widely used to produce NPs due to their biodegradability, biocompatibility, and mechanical resistance. In addition, PLGA is also approved by the Food and Drug Administration (FDA) for its use in various biomedical applications, such as absorbable sutures and implants, as well as for the development of sustained release systems [16,17]. Furthermore, compared to natural polymers, these synthetic polymers show greater reproducibility, are easier to formulate, and allow the control and prediction of degradation kinetics [18].

In addition, PLGA nanocarriers can be functionalized on their surface and targeted towards specific cells or ocular structures, increasing their transport across physiological barriers with a sustained and controlled release over time and reducing adverse effects of drugs [19,20]. PLGA nanocarriers minimize drug degradation and increase its half-life inside the target organ thus improving its efficacy and safety [21]. However, PLGA suffers from fast elimination in body tissues [22]. In order to overcome this problem, PEGylation is one of the most suitable approaches. Therefore, encapsulation of active compounds into poly(ethylene glycol) (PEG)-coated NPs offers the possibility to increase the transport across biological layers and increase drug protection against degradation [23].

Furthermore, during recent years, functionalization of NPs using cell-penetrating peptides (CPPs) has emerged as a new technology to facilitate the internalization of macromolecules and drugs in ocular cells, constituting a revolutionary approach due to their high transduction efficiency and low cytotoxicity [24,25]. CPPs are peptide sequences between 5 and 30 amino acids (AA) long with the ability to be internalized in the cell [26,27]. Among the different types of CPPs, cationic CPPs possess a highly positive surface charge due to their sequence rich in arginine residues (Arg) [28]. In this area, one of the most novel approaches is peptide functionalization of PLGA NPs by coupling selected CPPs to the NPs surface increasing cellular internalization. Among several peptides, Tet-1 and B6 were selected as suitable candidates for ocular drug delivery (Figure S1). Tet-1 is a 12-AA peptide, with the sequence HLNILSTLWKYR, which has the binding characteristics of tetanus toxin, can interact specifically with motor neurons, and is capable of retrograde delivery in the neuronal tissues due to its affinity to ganglioside GT1B receptor [29-31]. Therefore, Tet-1 peptide might increase cellular internalization also on the ocular tissues due to the presence of ganglioside receptors in this organ [30-33]. Moreover, a peptide showing high affinity to transferrin receptor (GHKAKGPRK, namely B6) has been described to increase transport 
across the BBB [20,34]. Since ocular tissues, and more specifically, corneal layers, have been reported to possess transferrin receptors, hereby, we postulate that B6 targeting may also be useful for ocular drug delivery [35-37]. To our knowledge, to date no attempt has been carried out using Tet-1 or B6 CPPs for surface functionalization aimed at ocular drug delivery.

Therefore, the main goal of this study was the entrapment of Lico-A inside surface functionalized Tet-1 or B6 PLGA-PEG NPs for ocular administration. PLGA NPs, synthesized by the solvent displacement method, were optimized using the design of experiments (DoE) approach, analyzing their physicochemical properties and stability. Subsequently, the study of drug release, ocular tolerance, and in vivo therapeutic efficacy of Lico-A PLGA NPs, Lico-A PLGA-PEG-Tet1 NPs, and Lico-A PLGA-PEG-B6 NPs was carried out.

\section{Materials and Methods}

\subsection{Materials}

The active compound Lico-A was obtained from Amadis Chemical (Hangzhou, China) and the polymer PLGA 50:50 Resomer ${ }^{\circledR}$ RG $503 \mathrm{H}, 34 \mathrm{KD}$, from Boehringer Ingelheim (Ingelheim, Germany). Maleimide-PEG-NH ${ }_{2}(5 \mathrm{KDa})$ was from Jenkem (Beijing, China). NovaSyn TGR resin and 9-fluorenyl-methoxycarbonyl (Fmoc) protected amino acids were purchased from Novabiochem (Merck Millipore, Merck KGaA, Darmstadt, Germany). Peptide-synthesis-grade dimethylformamide (DMF) and trifluroacetic acid (TFA) were obtained from Scharlau (Barcelona, Spain). HPLC-grade acetonitrile and acetone were purchased from Fisher Scientific (Loughborough, UK). The coupling reagent, 2-(1H-7azabenzotriazole-1-yl)-1,1,3,3- tetra-methyluronium hexafluorophosphate methanaminium (HATU) was from Genscript (Piscataway, NJ, USA). Diisopropylethylamine (DIPEA), piperidine, triisopropylsilane (TIS), 2-mercaptoethanol, $N$-(3-dimethylaminopropyl)- $N^{\prime}$ ethylcarbodiimide hydrochloride (EDC), $N$-hydroxysuccinimide (NHS), dimethyl sulfoxide (DMSO), dimethyl sulfoxide-d6 (DMSO-d6), and sodium arachidonic acid (SA) were purchased from Sigma-Aldrich (Merck KGaA, Darmstadt, Germany). Methanol and diethyl ether were purchased from Merck (KGaA, Darmstadt, Germany). Water filtered through the Millipore ${ }^{\circledR}$ MilliQ system was used for all experiments and the other chemicals and reagents used in the study were of analytical grade.

\subsection{Preparation of Licochalcone-A PLGA Nanoparticles}

For the elaboration of Lico-A PLGA NPs, the solvent displacement method was used $[38,39]$. Briefly, this technique consists of the preparation of two phases, namely organic and aqueous phases. First, $80 \mathrm{mg}$ of PLGA Resomer ${ }^{\circledR}$ RG $503 \mathrm{H}$ and $10 \mathrm{mg}$ of the drug Lico-A were dissolved in $5 \mathrm{~mL}$ of acetone (volatile organic solvent). Subsequently, this solution was dispersed dropwise, under moderate mechanical stirring, in $10 \mathrm{~mL}$ of the aqueous phase containing Tween 80; this process was carried out at room temperature. Afterwards, the organic solvent was evaporated from the suspension under reduced pressure using a rotary evaporator.

\subsection{Physicochemical Characterization of Licochalcone-A PLGA Nanoparticles}

In order to measure the physicochemical properties of Lico-A PLGA NPs, average size $\left(\mathrm{Z}_{\mathrm{av}}\right)$, polydispersity index $(\mathrm{PI})$, zeta potential $(\mathrm{ZP})$, and entrapment efficiency $(\mathrm{EE})$ were determined.

$\mathrm{Z}_{\mathrm{av}}$ and PI were placed in disposable cells (Malvern Instruments) and measured by photon correlation spectroscopy (PCS), after a 1:10 dilution with MilliQ ${ }^{\circledR}$ water, using the Zetasizer Nano ZS (Malvern Instruments, Malvern, UK) at $25^{\circ} \mathrm{C}$. The surface charge of the particles was evaluated by means of ZP and determined by laser-Doppler electrophoresis with the M3 PALS system in a Zetasizer Nano ZS (Malvern Instruments, Malvern, UK) [29].

$\mathrm{EE}$ was determined indirectly by measuring the non-entrapped Lico-A. The nonloaded drug was separated from NPs by ultracentrifugation at $4{ }^{\circ} \mathrm{C}$ and $25,000 \mathrm{rpm}$ for 
25 min, using a Beckman Optima ${ }^{\circledR}$ Ultracentrifuge (Indianapolis, IN, USA), and the EE was evaluated according to Equation (1) [30].

$$
\mathrm{EE}(\%)=\frac{\text { total amount of Lico }-\mathrm{A}-\text { free amount of Lico }-\mathrm{A}}{\text { total amount of Lico }-\mathrm{A}} \times 100
$$

Quantification of Lico-A in the aqueous phase was performed by reverse-phase high performance liquid chromatography (RP-HPLC) using a method described elsewhere [40,41]. HPLC Waters 2695 separation module (Waters, Milford, MA, USA) and a Kromasil ${ }^{\circledR}$ C18 column $(5 \mu \mathrm{m}, 150 \times 4.6 \mathrm{~mm})$ (Teknokroma Analítica, Barcelona, Spain) were employed. Moreover, two mobile phases were used consisting of a water phase containing $0.2 \%$ acetic acid and an organic phase consisting of acetonitrile. A gradient was applied at $1.0 \mathrm{~mL} \cdot \mathrm{min}^{-1}$ (during the first $10 \mathrm{~min}$ an initial 35\% mobile phase B was used until 100\% mobile phase B, maintaining this percentage for $7 \mathrm{~min}$ more, and after that it was progressively modified for 5 min until $100 \%$ of mobile phase A). For the calibration curve, a concentration range from 10 to $100 \mu \mathrm{g} \cdot \mathrm{mL}^{-1}$ was used. Agilent 1260 Infinity Variable Wavelength Detector VL standard version at a wavelength of $254 \mathrm{~nm}$ was utilized to identify Lico-A and data were handled using Empower $3^{\circledR}$ Software. Limit of detection (LOD) and limit of quantification (LOQ) were calculated as described elsewhere being 2.48 and $8.27 \mu \mathrm{g} \cdot \mathrm{mL}^{-1}$ [42].

\subsection{Optimization of Licochalcone-A PLGA Nanoparticles}

Optimization of Lico-A PLGA NPs was carried out prior to CPP addition by means of the Design of Experiments (DoE) approach. A $2^{3}$ central composite factorial design was carried out (Table 1) using StatGraphics Centurion XV, to analyze the effects of the independent variables over the dependent variables [43]. A total of 16 experiments were carried out by triplicate, with varying concentrations of drug (Lico-A), surfactant (Tween 80 ), and polymer. The effects of these variables on the dependent variables $\mathrm{Z}_{\mathrm{av}}, \mathrm{PI}, \mathrm{ZP}$, and EE were studied.

Table 1. Matrix of the factorial design.

\begin{tabular}{cccccc}
\hline \multicolumn{7}{c}{ Coded Levels } \\
\hline Variables & -1.68 & -1.00 & 0.00 & 1.00 & 1.68 \\
\hline Lico-A $(\mathrm{mg} / \mathrm{mL})$ & 0.16 & 0.50 & 1.00 & 1.50 & 1.80 \\
\hline PLGA $(\mathrm{mg} / \mathrm{mL})$ & 4.16 & 4.50 & 5.00 & 5.50 & 5.84 \\
\hline Tween $80(\%)$ & 0.46 & 0.60 & 0.80 & 1.00 & 1.14 \\
\hline
\end{tabular}

\subsection{Short-Term Stability of Licochalcone-A PLGA Nanoparticles}

The stability of Lico-A PLGA NPs stored at 4,25 , and $38^{\circ} \mathrm{C}$ was studied by analyzing light backscattering (BS) profiles by means of Turbiscan ${ }^{\circledR}$ Lab (Formulaction, Toulouse, France) [44]. For this purpose, $20 \mathrm{~mL}$ of Lico-A PLGA NPs were introduced into a glass measurement cell. The light source was a pulsed near infrared light source $(\lambda=880 \mathrm{~nm})$ and it was detected by a BS detector at an angle of $45^{\circ}$ from the incident beam. BS data were obtained scanning the sample every hour during $24 \mathrm{~h}$. The mean results of each month were plotted and BS profiles were compared monthly at each temperature.

\subsection{Synthesis of Cell Penetrating Peptides}

CPPs, Tet-1, and B6 (Figure S1) were selected based on their high affinity for cell receptors and were synthesized by manual solid phase synthesis following a 9-fluorenylmethoxycarbonyl/tbutyl (Fmoc/tBut) orthogonal protection strategy [45]. The C-terminal amino acid (AA) remains anchored to a resin (NovaSyn TGR $0.19 \mathrm{meq} / \mathrm{g}$ for Tet- 1 and $0.22 \mathrm{meq} / \mathrm{g}$ for peptide B6) bound by its carboxyl group while the peptide is synthesized by elongating the chain at the $\mathrm{N}$-terminal end. Amino acid side-chain 
protection was carried out using the following compounds: triphenylmethyl (Trt) for asparagine and histidine; tert-butyl (tBu) for serine, threonine, and tyrosine; 2,2,5,7,8pentamethyl-chroman-6-sulfonyl (Pmc) for arginine and tert-butoxycarbonyl (Boc) for lysine and tryptophan. A residue of Fmoc-S-triphenylmethyl-L-cysteine (Fmoc-Cys(Trt)$\mathrm{OH})$ was incorporated at the N-terminal end of both peptides, Tet-1 and B6, for their conjugation to the polymer. Sequential incorporation of the Fmoc-L-amino acids is accomplished through a series of coupling and deprotection steps. The coupling reactions were performed using three-fold molar excesses of the amino acid derivatives activated by treatment with HATU and DIPEA throughout the synthesis. The Fmoc deprotection was accomplished twice with $20 \%(v / v)$ piperidine in DMF for $10 \mathrm{~min}$. All coupling and deprotection steps were checked by the ninhydrin test for primary amines, or the chloranil test for secondary amino groups. Finally, peptides were cleaved from the solid support by means of treatment with TFA/TIS/ $\mathrm{H}_{2} \mathrm{O} / 2$-mercaptoethanol (94:2.5:2.5:1) $(v / v)$ for $5 \mathrm{~h}$. The TFA was evaporated under $\mathrm{N}_{2}$ flow. Diethyl ether was added to precipitate the crude peptides, which were isolated by centrifugation. The precipitates were dissolved in acetic acid 10\%, frozen in a dry ice/acetone bath, and lyophilized. The peptides were stored in an argon environment to avoid their possible oxidation. Peptides were characterized by Ultra performance Liquid Chromatography-Mass Spectrometry (UPLC-MS) on Waters ACQUITY UPLC (Waters Corporation, Mildford, MA, USA) with the column ACQUITY UPLC BEH C18 (RP, $2.1 \times 100 \mu \mathrm{m}$, particle size $1.7 \mu \mathrm{m}$ ) with both a UV-Vis detector and an electrospray ionization mass spectrometer (ESI-MS) Waters LCT Premier XE (Micromass Waters, Milford, MA, USA).

\subsection{Conjugation of PEG and Cell Penetrating Peptides (CPPS) to the Polymer and Preparation of} Lico-A PLGA-PEG-CPP NPS

In order to functionalize PLGA (Figure 1), first the PLGA-NHS polymer was synthesized, for which the equivalent of $32.3 \mu \mathrm{mol}$ of PLGA 50:50 Resomer ${ }^{\circledR}$ RG $503 \mathrm{H}$ (inherent viscosity $0.32-0.44 \mathrm{dL} / \mathrm{g}$ ) was weighed out and dissolved in $2 \mathrm{~mL}$ of chloroform. Subsequently, $234.6 \mu \mathrm{mol}$ of NHS and the same equivalents of EDC were added and the mixture was left to react for between 16 and $24 \mathrm{~h}$ under continuous mechanical stirring in a hermetically sealed glass vial at room temperature. Once the PLGA-NHS was obtained, it was precipitated with cold diethyl ether and centrifuged at $4000 \mathrm{rpm}$ for $10 \mathrm{~min}$ at room temperature. After removing the supernatant, the pellet was redissolved in $2 \mathrm{~mL}$ of chloroform and precipitated with cold diethyl ether. This dissolution-precipitation process was carried out in triplicate. The PLGA-NHS polymer obtained was dried using nitrogen gas $\left(\mathrm{N}_{2}\right)$ and lyophilized.

Subsequently the activated polymer was conjugated with maleimide-PEG-NH $\mathrm{H}_{2}$ and DIEA was used as the activator. The obtained PLGA-PEG-maleimide copolymer was lyophilized and stored at $-20^{\circ} \mathrm{C}$.

The conjugation of the selected peptides to the PLGA-PEG-maleimide polymer was carried out by dissolving $2.7 \mu \mathrm{mol}$ of each CPP in $250 \mu \mathrm{L}$ of acetonitrile/DMF and was added later to a solution of $100 \mathrm{mg}$ of dissolved PLGA-PEG-maleimide in $1 \mathrm{~mL}$ of chloroform. The reaction was left for 16-24 h under magnetic stirring at room temperature. The product was precipitated with $1 \mathrm{~mL}$ of cold ether:methanol (50:50) and centrifuged at $10,000 \mathrm{rpm}$ for $10 \mathrm{~min}$. The supernatant was discarded, and the product was redissolved in $0.5 \mathrm{~mL}$ of chloroform. This cycle was repeated two additional times [11]. The final product was lyophilized and stored at $-20^{\circ} \mathrm{C}$. Conjugation evaluation was carried out by proton nuclear magnetic resonance (1H-NMR) as previously described [19]. The PLGAPEG-maleimide was dissolved in deuterated chloroform and the PLGA-PEG-peptide in dimethyl sulfoxide (DMSO)-d6. The spectrum was recorded at $298 \mathrm{~K}$ on a Varian Inova $400 \mathrm{MHz}$ spectrometer (Agilent Technologies, Santa Clara, CA, USA). PLGA-PEG-CPP NPs containing Lico-A were prepared by the solvent displacement method as described in Section 2.2. The physicochemical properties of Lico-A PLGA-PEG-CPP NPs were determined as described in Section 2.3. 

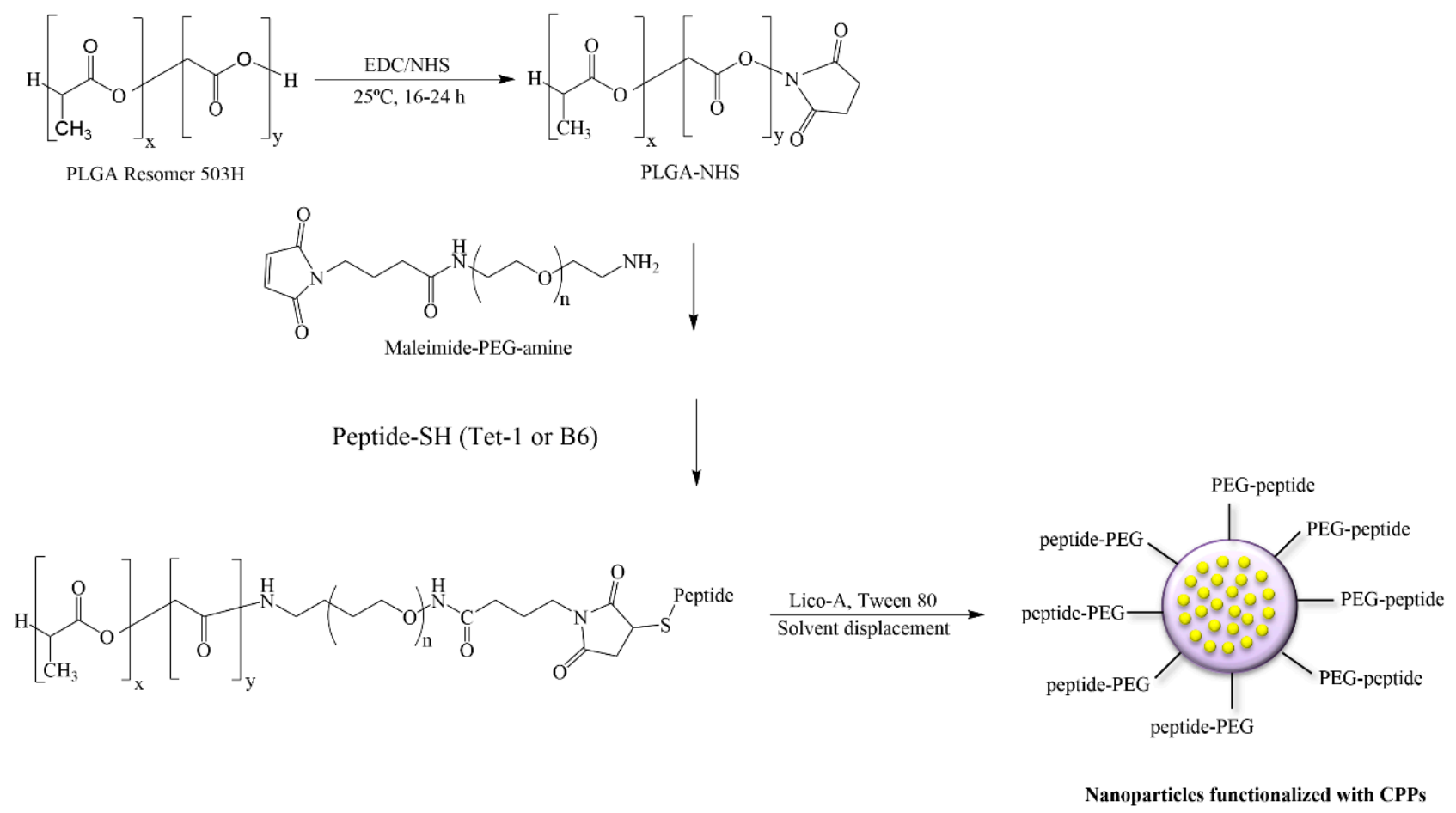

Figure 1. Conjugation of PEG and cell penetrating peptides (CPPs) to PLGA and preparation of Lico-A PLGA-PEG-CPP NPs.

\subsection{Transmission Electron Microscopy of Licochalcone-A Functionalized Nanoparticles}

Morphologies of Lico-A PLGA NPs, Lico-A -PLGA-PEG-Tet1 NPs, and Lico-A PLGAPEG-B6 NPs were studied by transmission electron microscopy (TEM) on a JEOL 1010 microscope (Akishima, Japan). To visualize the NPs, samples were previously diluted (1:5) and the Holey Carbon grids were activated with UV light. Samples were placed on the grid surface and negative staining was performed with uranyl acetate (2\%) [46].

\subsection{Drug Release of Licochalcone-A Functionalized Nanoparticles}

The in vitro release profiles of Lico-A PLGA NPs, Lico-A PLGA-PEG-Tet1 NPs, and Lico-A PLGA-PEG-B6 NPs from the polymeric matrix were determined by bulk-equilibrium direct dialysis [47]. Briefly, $9 \mathrm{~mL}$ of Lico-A NPs were placed in a dialysis bag (Medicell International Ltd. MWCO 12-14,000) and dialyzed against $150 \mathrm{~mL}$ of release medium. In order to accomplish sink conditions, release medium was composed of ethanol-water $75: 25$, at $32{ }^{\circ} \mathrm{C}$ (temperature of corneal surface) and $0.3 \mathrm{~mL}$ of samples were withdrawn at regular time intervals during $24 \mathrm{~h}$ [48]. Lico-A content was analyzed by HPLC as previously described. Moreover, the total volume of release medium was kept constant by replacement with fresh medium throughout the experiment.

\subsection{Ocular Tolerance of Licochalcone-A Functionalized Nanoparticles}

\subsubsection{In Vitro Ocular Tolerance}

In order to assess the in vitro ocular tolerance, the HET-CAM (hen's egg-chorioallantoic membrane) test was developed as described in the INVITTOX protocol No. 15 [49,50]. This method is based on the observation of the irritating effects (hemorrhage, vasoconstriction, and coagulation) that may appear during the first five minutes after the application of $300 \mu \mathrm{L}$ of the studied formulation on the chorioallantoic membrane (CAM) of a 10-day embryonated egg. These eggs were kept at a temperature of $12 \pm 1^{\circ} \mathrm{C}$ for at least $24 \mathrm{~h}$ before placing them in the incubator with controlled temperature $\left(37.8^{\circ} \mathrm{C}\right)$ and humidity $(50-60 \%)$ during the days of incubation [46]. Free Lico-A (dissolved in DMF:PEG 400:MQ Water; 1:49:50), Lico-A PLGA NPs, and Lico-A PLGA-PEG-CPP NPs were evaluated. Controls 
were created using SDS 1\% (positive control for slow irritation), $\mathrm{NaOH} 0.1 \mathrm{~N}$ (positive control for rapid irritation), and $\mathrm{NaCl} 0.9 \%$ (negative control).

Data were analyzed by calculating the ocular irritation index (OII) by applying Equation (2) ( $n=3 /$ group).

$$
\mathrm{OII}=\frac{301-H}{300} \times 5+\frac{301-V}{300} \times 7+\frac{301-C}{300} \times 9
$$

where $H$ is the time in seconds in which the hemorrhage appears; $V$ is the time in seconds in which vasoconstriction appears; $C$ is the time in seconds in which coagulation appears.

According to the OII score, the products were classified into four categories as described elsewhere [44].

\subsubsection{In Vivo Ocular Tolerance}

In order to confirm the in vitro results, the primary eye irritation test of Draize et al. was used [46,51]. Young adult male albino New Zealand rabbits with an average weight of $2.5 \mathrm{~kg}$ housed in individual cages were used. Animals were maintained in controlled temperature $\left(17-23^{\circ} \mathrm{C}\right)$ and relative humidity $(60-80 \%)$ conditions with food and water supplemented ad libitum. This test was carried out in accordance with the Ethical Committee for Animal Experimentation of the University of Barcelona and current legislation (Decree 214/97, Gencat). The products Lico-A PLGA NPs, Lico-A PLGA-PEG-Tet-1 NPs, and Lico-A PLGA-PEG-B6 NPs were evaluated. Each product $(50 \mu \mathrm{L})$ was instilled in the conjunctival sac of the right eye and a gentle massage was applied to ensure correct circulation of the sample. Readings were carried out $30 \mathrm{~min}$ after the application of the sample, using the left eye as a negative control ( $n=3$ /group). OII was determined as previously described elsewhere [52].

\subsection{Anti-Inflammatory Therapeutic Efficacy of Licochalcone-A Functionalized Nanoparticles}

The ability of the developed formulations to revert to ocular inflammation was demonstrated in New Zealand rabbits. Therefore, Lico-A PLGA NPs, Lico-A PLGA-PEG-Tet-1 NPs, and Lico-A PLGA-PEG-B6 NPs were evaluated in vivo in New Zealand rabbits [52].

In order to induce ocular inflammation, $50 \mu \mathrm{L}$ of SA $0.5 \%(w / v)$ dissolved in PBS (pH 7.4) were instilled in the right eye. After $30 \mathrm{~min}$ of the induction of inflammation, $50 \mu \mathrm{L}$ of each formulation (Lico-A PLGA NPs, Lico-A PLGA-PEG-Tet-1 NPs, and Lico-A PLGAPEG-B6 NPs or isotonic saline serum) were instilled in the conjunctival sac of the right eye, using the left eye as a control. Inflammation was evaluated $30 \mathrm{~min}$ after instillation of the formulations, and then at 60, 90, 120, 150, 180, and $210 \mathrm{~min}$, according to a modified Draize scoring system $[53,54]$. Ocular inflammation score was calculated and expressed as mean \pm SD. Moreover, inhibition inflammation \% was also calculated according to Equation (3):

$$
\text { Inflammation inhibition }(\%)=\frac{\mathrm{C}-\mathrm{T}}{\mathrm{C}} \times 100
$$

$\mathrm{C}=$ saline serum ocular inflammation (control group)

$\mathrm{T}=$ treated group ocular inflammation

\subsection{Statistical Analysis}

Statistical analyses were performed by using one-way ANOVA with Tukey post hoc test. All analyzed data were presented as mean \pm SD. GraphPad Prism ${ }^{\circledR} 6.01$ software was used to analyze the data.

\section{Results and Discussion}

\subsection{Optimization and Characterization of Licochalcone-A PLGA NPS}

In order to optimize the formulation, Lico-A PLGA NPs were prepared by solvent displacement technique and optimized by DoE, analyzing the effect of independent variables (drug, surfactant, and polymer concentrations) on the dependent variables ( $\mathrm{Z}_{\mathrm{av}}, \mathrm{PI}, \mathrm{ZP}$, 
and EE). The results obtained for different formulations of the central composite factorial design can be observed in Table 2 .

Table 2. Results of the factorial design developed to optimize Lico-A NPs formulation.

\begin{tabular}{|c|c|c|c|c|c|c|c|c|c|c|}
\hline \multirow{3}{*}{$\begin{array}{l}\text { Experiment } \\
\text { Number }\end{array}$} & \multicolumn{6}{|c|}{ Independent Variables } & \multicolumn{4}{|c|}{ Dependent Variables } \\
\hline & \multicolumn{2}{|c|}{ Lico-A } & \multicolumn{2}{|c|}{ PLGA } & \multicolumn{2}{|c|}{ Tween 80} & \multirow{2}{*}{$\mathrm{Z}_{\mathrm{av}}(\mathrm{nm})$} & \multirow{2}{*}{ PI } & \multirow{2}{*}{$\mathrm{ZP}(\mathrm{mV})$} & \multirow{2}{*}{ EE (\%) } \\
\hline & Coded Level & $\mathrm{mg} / \mathrm{mL}$ & Coded Level & $\mathrm{mg} / \mathrm{mL}$ & Coded Level & $\%$ & & & & \\
\hline 1 & -1 & 0.5 & -1 & 4.5 & -1 & 0.6 & 130.6 & 0.103 & -39.2 & 18.80 \\
\hline 2 & 1 & 1.5 & -1 & 4.5 & -1 & 0.6 & 144.8 & 0.098 & -36.3 & 55.43 \\
\hline 3 & -1 & 0.5 & -1 & 4.5 & 1 & 1.0 & 126.7 & 0.091 & -35.4 & 10.38 \\
\hline 4 & 1 & 1.5 & -1 & 4.5 & 1 & 1.0 & 130.4 & 0.088 & -31.8 & 19.92 \\
\hline 5 & -1 & 0.5 & 1 & 5.5 & -1 & 0.6 & 136.0 & 0.078 & $-32,7$ & 30.04 \\
\hline 6 & 1 & 1.5 & 1 & 5.5 & -1 & 0.6 & 155.0 & 0.082 & -33.4 & 61.72 \\
\hline 7 & -1 & 0.5 & 1 & 5.5 & 1 & 1.0 & 166.1 & 0.103 & -33.8 & 7.02 \\
\hline 8 & 1 & 1.5 & 1 & 5.5 & 1 & 1.0 & 143.5 & 0.079 & -31.6 & 32.32 \\
\hline 9 & 1.68 & 1.84 & 0 & 5.0 & 0 & 0.8 & 149.6 & 0.095 & -31.7 & 59.53 \\
\hline 10 & -1.68 & 0.16 & 0 & 5.0 & 0 & 0.8 & 129.6 & 0.100 & -37.8 & 35.55 \\
\hline 11 & 0 & 1.0 & 0 & 5.0 & 1.68 & 1.136 & 134.8 & 0.111 & -31.3 & 8.65 \\
\hline 12 & 0 & 1.0 & 0 & 5.0 & -1.68 & 0.464 & 135.7 & 0.085 & -33.4 & 45.46 \\
\hline 13 & 0 & 1.0 & 1.68 & 5.84 & 0 & 0.8 & 139.5 & 0.088 & -35.1 & 16.25 \\
\hline 14 & 0 & 1.0 & -1.68 & 4.16 & 0 & 0.8 & 124.4 & 0.096 & -31.6 & 12.50 \\
\hline 15 & 0 & 1.0 & 0 & 5.0 & 0 & 0.8 & 132.9 & 0.092 & -32.6 & 13.62 \\
\hline 16 & 0 & 1.0 & 0 & 5.0 & 0 & 0.8 & 128.1 & 0.099 & -30.5 & 14.14 \\
\hline
\end{tabular}

Data obtained was analyzed in order to observe the trends that Lico-A PLGA NPs follow. Regarding the $Z_{\mathrm{av}}$, it can be observed that low Lico-A concentrations are able to provide smaller NPs size (Figure 2A). Moreover, high PLGA amounts tend to slightly increase NPs $Z_{\mathrm{av}}$ (Figure S2). This fact correlates with previous studies carried out using polymeric NPs where increased PLGA concentration causes higher $Z_{\mathrm{av}}$ [43]. Moreover, $Z_{\mathrm{av}}$ varies when low surfactant concentrations are used observing that at high surfactant amounts lower $Z_{\mathrm{av}}$ is obtained. Importantly, even with low surfactant amounts, all the formulations obtained showed $Z_{\mathrm{av}}$ below $200 \mathrm{~nm}$. Moreover, increased amounts of Tween 80 favor lower PI values and, as observed for $Z_{\mathrm{av}}$, high Lico-A amounts tend to increase the PI (Figure 2B). Therefore, medium-low Lico-A concentrations will be used in order to reduce PI. Moreover, as can be observed in the Pareto chart, low amounts of Tween 80 also favor the EE (Figure 2C). Concerning this parameter, low Lico-A values tend to increase the $\mathrm{EE}(p<0.05)$ (Figure 2D). This might be due to the fact that it is easier to encapsulate low amounts of drug, thus obtaining high EE values.

After analyzing the trends obtained and due to the fact that even at high PLGA amounts all Lico-A loaded NPs showed average sizes below $200 \mathrm{~nm}$, the optimized formulation was developed and characterized containing $1 \mathrm{mg} / \mathrm{mL}$ of Lico-A, $8 \mathrm{mg} / \mathrm{mL}$ of PLGA, and $0.4 \%$ Tween. The physicochemical properties of the optimized NPs were suitable for ocular drug delivery since $Z_{\mathrm{av}}(163.81 \pm 2.29)$ was below $200 \mathrm{~nm}$, PI (0.075 \pm 0.010$)$ corresponded to monodisperse particles, ZP $(-24 \pm 1.4)$ was highly negative, and EE $(56.26 \pm 0.16)$ was superior to $50 \%$. 
A)

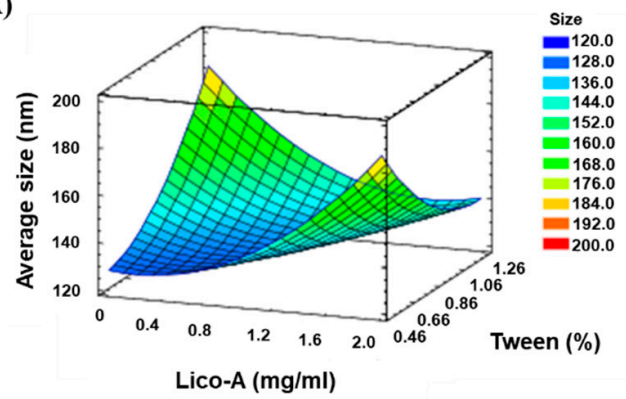

C)

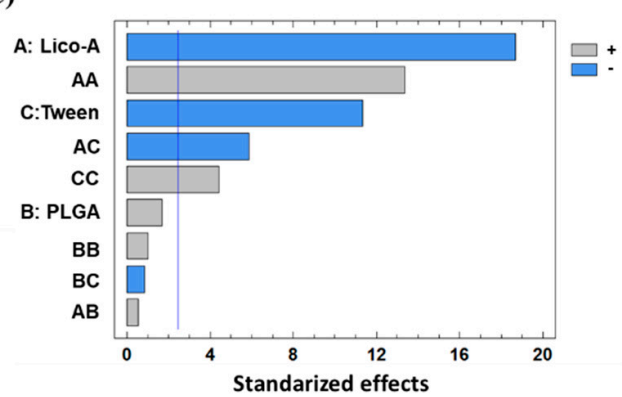

B)

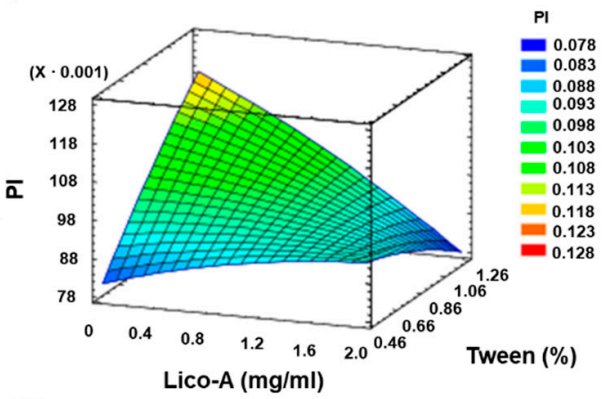

D)

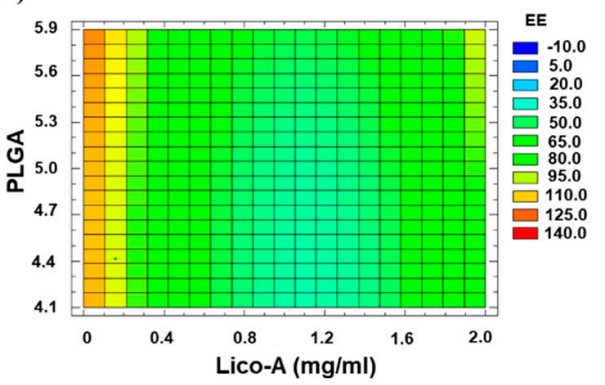

Figure 2. Design of experimental results. (A) Surface response plot for $\mathrm{Z}_{\mathrm{av}}$, (B) Surface response plot for PI, (C) Pareto chart for EE (A: Lico-A concentration; B: PLGA concentration; C: Tween concentration; vertical blue line indicates significant effect), (D) Contoured surface response plot for EE.

\subsection{Short-Term Stability of Licochalcone-A PLGA NPS}

The optimized Lico-A PLGA NPs were stored at three different temperatures $(4,25$, and $38{ }^{\circ} \mathrm{C}$ ) in order to study their short-term stability. As can be observed in Figure 3, Lico-A PLGA NPs were stable at $4{ }^{\circ} \mathrm{C}$ and $25^{\circ} \mathrm{C}$ even after 3 months of storage. However, at $38^{\circ} \mathrm{C}$, the formulations were clearly unstable obtaining variations of the BS superior to $10 \%[55,56]$. These results correlate with other obtained by previous authors using PLGA nanocarriers [43]. Moreover, differences in the BS profile at 4 and $25{ }^{\circ} \mathrm{C}$ were below $10 \%$, which indicates a suitable short-term stability at both temperatures. However, a slight difference after two months of storage can be observed at $25{ }^{\circ} \mathrm{C}$ which may indicate an initial instability process, whereas at $4{ }^{\circ} \mathrm{C}$ the profiles were almost identical. Therefore, $4{ }^{\circ} \mathrm{C}$ will be the most suitable temperature for storing Lico-A PLGA NPs.

\subsection{Synthesis of CPP and Polymer Conjugation}

In order to functionalize Lico-A PLGA NPs, two CPPs were synthesized by solid phase peptide synthesis. A residue of Cys was incorporated at the N-terminal end of both Tet-1 and B6 peptides to perform a covalent linkage with the PLGA-PEG-maleimide copolymer previously synthesized. Peptide characterization by ESI-MS is shown in Table S1 of the supplementary material. The PLGA polymer was activated with NHS and covalently coupled to the maleimide-PEG- $\mathrm{NH}_{2}$ by formation of an amide group in liquid phase. Afterwards, conjugation of PLGA-PEG-maleimide with CPP Tet-1 and B6 was carried out in solution, being confirmed by ${ }^{1} \mathrm{H}-\mathrm{NMR}$. 
А)

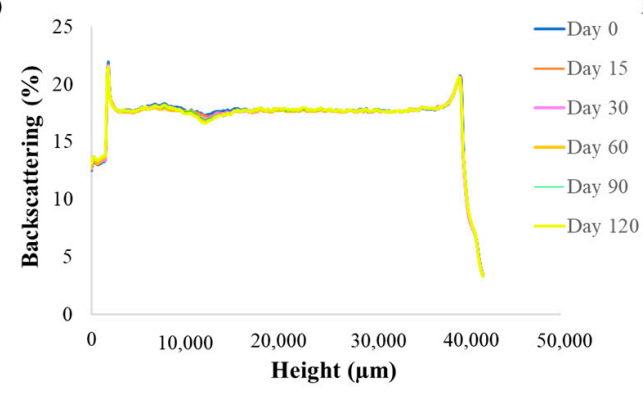

C)
B)

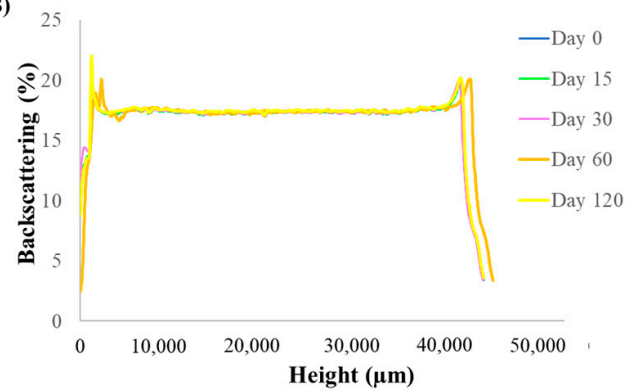

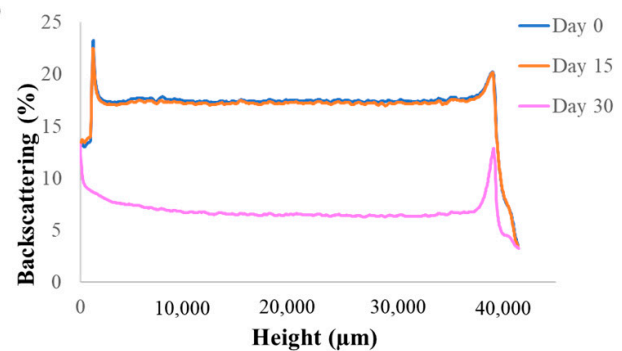

Figure 3. Turbiscan backcattering profile at different temperatures analyzed monthly. (A) $4{ }^{\circ} \mathrm{C}$, (B) $25^{\circ} \mathrm{C}$ and (C) $38{ }^{\circ} \mathrm{C}$.

\subsection{Physicochemical Characterization of Licochalcone-A Functionalized Nanoparticles}

Table 3 shows the results of the physicochemical properties of surface functionalized Lico-A NPs. It can be observed that both formulations (Lico-A PLGA-PEG-Tet1 NPs and Lico-A PLGA-PEG-B6 NPs) show optimal physicochemical properties for ocular administration. Interestingly, the conjugation of a CPP to the polymer allows to obtain Lico-A NPs with lower $Z_{\mathrm{av}}$, probably due to polymer interactions with the positive peptide charge compacting the NPs core. Moreover, CPP conjugation increases the PI in a slight manner, but all the formulations PI remain below 0.2. However, it can be observed that average size and PI of Lico-A PLGA-PEG-Tet1 NPs are slightly higher than Lico-A PLGAPEG-B6 NPs probably because B6 has a higher positive AA ratio (4 positive AA / 9 total AA) than Tet-1 (2 positive AA/12 total AA). Therefore, B6 higher positive charge may favor PLGA interaction, thus contributing to smaller and more homogeneous NPs than Tet-1. In addition, ZP of the obtained peptide targeted NPs showed a surface charge modification from negative to highly positive. This has been previously described by other authors using CPP [8]. Furthermore, this positive charge will ensure better interaction with corneal tissues due to their negative charge [57]. The EE values of Lico-A PLGA-PEG-B6 NPs are significantly lower than Lico-A PLGA NPs and Lico-A PLGA-PEG-Tet-1 NPs where the $\mathrm{EE}$ is higher than $50 \%$ of the initial drug added. This may be due to the smaller Lico-A PLGA-PEG-B6 NPs $Z_{a v}$ that might cause lower EE values [58].

Table 3. Physicochemical parameters of the optimized formulation $(1 \mathrm{mg} / \mathrm{mL}$ of Lico-A, $8 \mathrm{mg} / \mathrm{mL}$ of PLGA, and $0.4 \%$ Tween 80 ) without peptide addition, with PEG and Tet- 1 peptide, and with PEG and B6 peptide.

\begin{tabular}{ccccc}
\hline Formulation & $\mathbf{Z}_{\mathbf{a v}}(\mathbf{n m}) \pm \mathbf{S D}$ & $\mathbf{P I} \pm \mathbf{S D}$ & $\mathbf{Z P} \pm \mathbf{S D}$ & $\mathbf{E E}$ (\%) \\
\hline Lico-A PLGA NPs & $163.81 \pm 2.29$ & $0.075 \pm 0.010$ & $-24.2 \pm 1.4$ & $56.26 \pm 0.16$ \\
Lico-A PLGA-PEG-Tet-1 NPs & $128.65 \pm 7.53$ & $0.149 \pm 0.016$ & $16.02 \pm 0.58$ & $53.26 \pm 0.62$ \\
Lico-A PLGA-PEG-B6 NPs & $114.24 \pm 2.42$ & $0.122 \pm 0.012$ & $10.49 \pm 1.02$ & $31.36 \pm 0.60$ \\
\hline
\end{tabular}

\subsection{Morphology of Licochalcone-A Functionalized Nanoparticles}

Lico-A PLGA NPs, Lico-A PLGA-PEG-Tet-1 NPs, and Lico-A PLGA-PEG-B6 NPs were observed by TEM after negative staining (Figure 4). In all the cases, Lico-A loaded NPs showed a spherical shape and a smooth surface, characteristic of this type of drug delivery 
system, without any aggregation phenomena [52]. As expected, NPs size measured by TEM was similar to the size obtained by PCS [59].

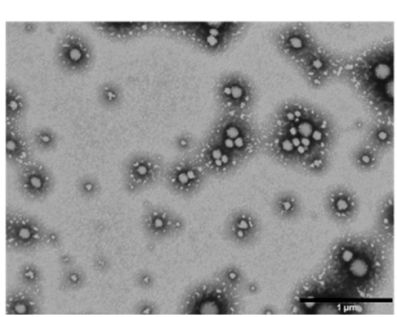

B)

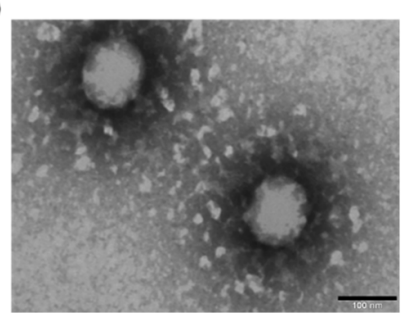

C)

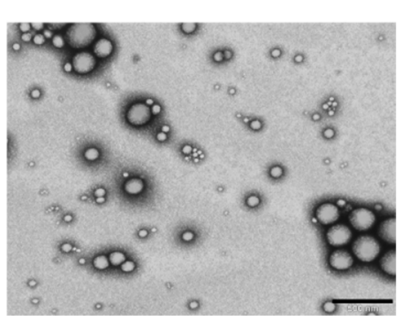

Figure 4. Transmission electron microscopical images of Lico-A NPs. (A) Lico-A-PLGA NPs (scale bar corresponds to $1 \mu \mathrm{m}$ ), (B) Lico-A PLGA-PEG-Tet-1 NPs (scale bar corresponds to $100 \mathrm{~nm}$ ), and (C) Lico-A PLGA-PEG-B6 NPs (scale bar corresponds to $500 \mathrm{~nm}$ ).

\subsection{Drug Release of Licochalcone-A Functionalized Nanoparticles}

In order to study the release of Lico-A from Lico-A PLGA NPs, Lico-A PLGA-PEG-Tet1 NPs, and Lico-A PLGA-PEG-B6 NPs, a direct dialysis experiment was carried out. In all Lico-A NPs, an initial fast release corresponding to a burst effect of the Lico-A placed on the NPs surface followed by a sustained Lico-A release can be observed (Figure 5).

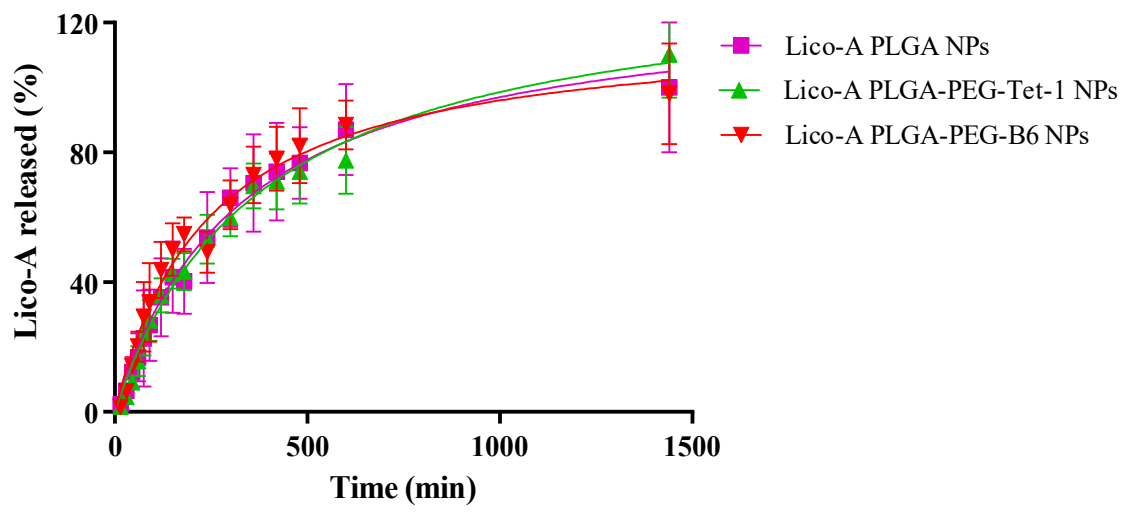

Figure 5. Lico-A release profile carried out by direct dialysis method for studying several formulations (Lico-A PLGA NPs, Lico-A PLGA-PEG-Tet1 NPs, and Lico-A-PLGA-PEG-B6 NPs).

Moreover, release profiles of all the formulations were very similar, being able to release Lico-A within the first $24 \mathrm{~h}$ after their application. In addition, this release from biodegradable nanocarriers is usually governed by a diffusion process since it is much faster than the matrix degradation [55]. Release data were fitted to a hyperbola equation [60-62]. Although all of the formulations were very similar, as can be observed in Table 4, Lico-A PLGA-PEG-Tet-1 NPs showed the higher $\mathrm{K}_{\mathrm{d}}$ (equilibrium dissociation constant) thus meaning that diffusion of Lico-A is slower than the observed in the other formulations, indicating that the formulation obtained with the Tet-1 peptide conjugated to the polymer is able to delay Lico-A delivery. Moreover, in all cases, $\mathrm{B}_{\max }$ was around $100 \%$, thus indicating that all of the Lico-A encapsulated is released within $24 \mathrm{~h} \mathrm{[43].}$ 
Table 4. Release data fitted to a hyperbola equation (meaning $\mathrm{K}_{\mathrm{d}}$, half of the time when Lico-A is released at equilibrium and $\mathrm{B}_{\max }$ maximum $\%$ of Lico-A released).

\begin{tabular}{cccc}
\hline & Lico-A PLGA NPs & Lico-A PLGA-PEG-Tet-1 NPs & Lico-A PLGA-PEG-B6 NPs \\
\hline $\mathrm{B}_{\max }(\%)$ & $128.9 \pm 9.3$ & $136.0 \pm 10.6$ & $119.3 \pm 9.5$ \\
$\mathrm{~K}_{\mathrm{d}}(\mathrm{min})$ & $328.6 \pm 51.4$ & $379.3 \pm 61.6$ & $242.0 \pm 46.4$ \\
\hline \multicolumn{4}{c}{ Goodness of Fit } \\
\hline $\mathrm{R}^{2}$ & 0.8937 & 0.8891 & 0.8338 \\
\hline
\end{tabular}

\subsection{Ocular Tolerance of Licochalcone-A Surface Functionalized Nanoparticles}

The potential risk of eye irritation caused by the developed formulations was evaluated by ocular tolerance tests using in vitro and in vivo methods.

An in vitro HET-CAM test was carried out and OII was calculated. Images were recorded before and after $5 \mathrm{~min}$ of the product application to the CAM (Figure 6). Moreover, OII was calculated showing that neither Lico-A PLGA NPs, Lico-A PLGA-PEG Tet-1 NPs, nor Lico-A PLGA-PEG-B6 NPs were irritants. Therefore, all the formulations obtained an OII around 0 without observing any irritation phenomena and they were classified as non-irritant.

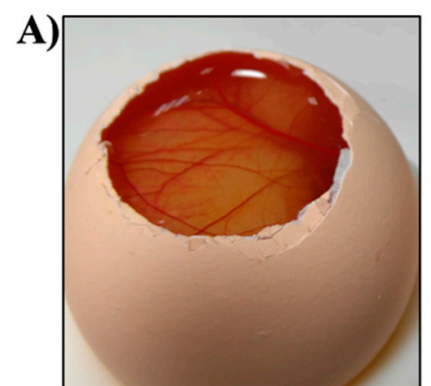

D)

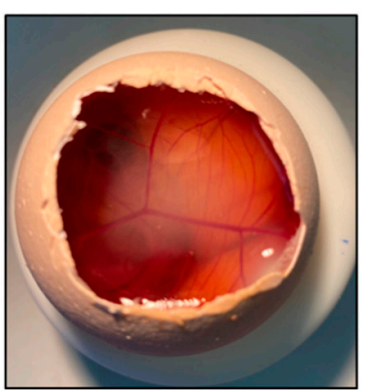

B)

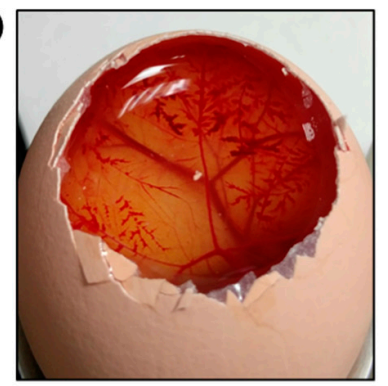

E)

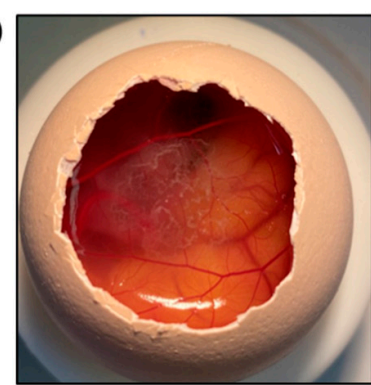

C)

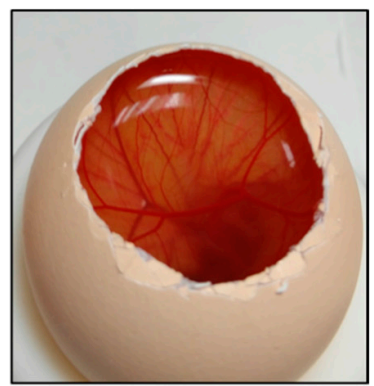

F)

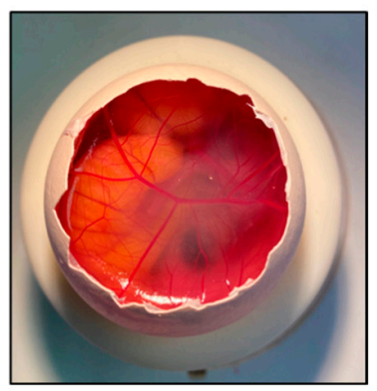

Figure 6. HET-CAM assessment images after 5 min of the product application. (A) NaCL, (B) $\mathrm{NaOH}$, (C) SDS 1\%, (D) Lico-A PLGA NPs, (E) Lico-A PLGA-PEG-Tet-1 NPs, (F) Lico-A PLGA-PEG-B6 NPs.

However, since the in vitro results are not able to reproduce all of the in vivo conditions, Draize eye irritation of free Lico-A, Lico-A PLGA NPs, Lico-A PLGA-PEG-Tet1 NPs, and Lico-A PLGA-PEG-B6 NPs was carried out to confirm the HET-CAM classification [63].

The results of the in vivo test showed excellent ocular tolerance for all the formulations evaluated (Figure S3). No signs of eye irritation were detected in any of the formulations, being classified as non-irritating substances. Therefore, these results agree with those obtained by the HET-CAM test confirming its suitability for the evaluation of the ocular tolerance of pharmaceutical products [44].

\subsection{Anti-Inflammatory Therapeutic Efficacy of Licochalcone-A Functionalized Nanoparticles}

The anti-inflammatory efficacy of the Lico-A NPs functionalized with Tet-1 or B6 peptides was assessed in a model of ocular inflammation.

As can be observed in Figure 6, during the first timepoints, all of the Lico-A NPs and free Lico-A showed statistically significant differences against the control group $(p<0.001)$. 
This may be due to the potent Lico-A anti-inflammatory capacity previously reported by other groups and demonstrated here for ocular applications $[64,65]$. Among all the formulations, Lico-A PLGA-PEG-B6 NPs presented significantly increased anti-inflammatory activity compared to the other formulations and free Lico-A (Figure 7). This correlates with the faster initial Lico-A release obtained in vitro as well as with the fact that B6 peptide has a higher positive charge than Tet-1, thus increasing the interactions with negative ocular layers and allowing Lico-A enhanced penetration and therapeutic effects. Furthermore, Lico-A PLGA-PEG-B6 NPs also possess a smaller average size which may facilitate their cellular internalization and pharmacological effects [66]. Moreover, free Lico-A showed an initial superior activity compared to Lico-A PLGA NPs and Lico-A PLGA-PEG-Tet1 NPs but after 90 min no significant differences between the formulations were obtained. Moreover, all of the assessed formulations were able to reduce inflammation compared to the saline serum control in a significant manner, even after $210 \mathrm{~min}$ after the inflammation induction.

A)

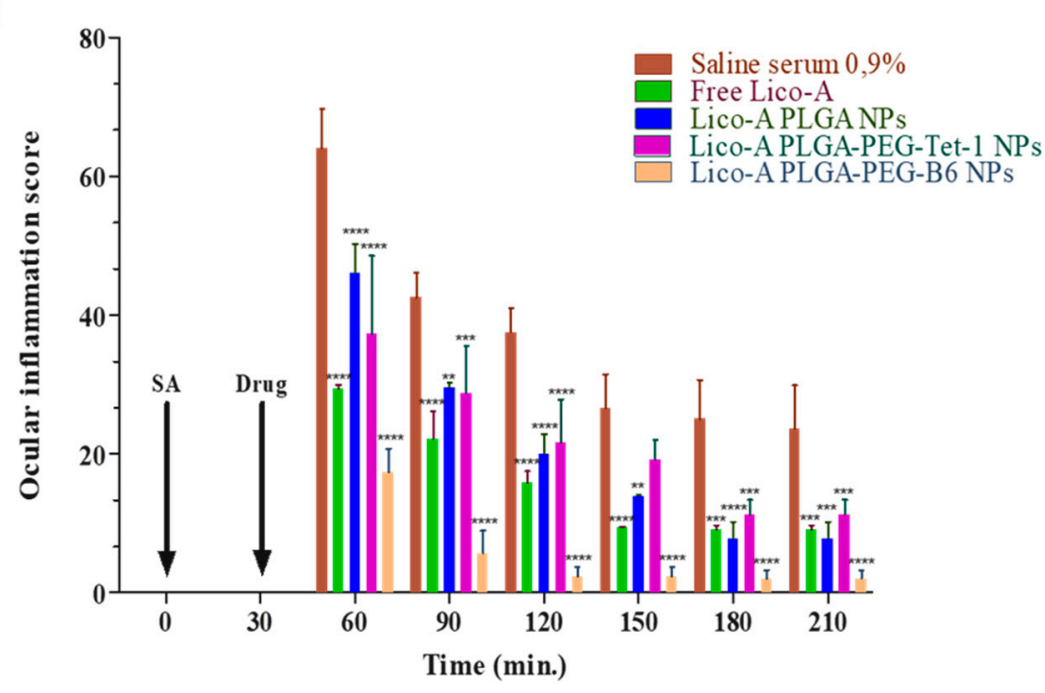

B)

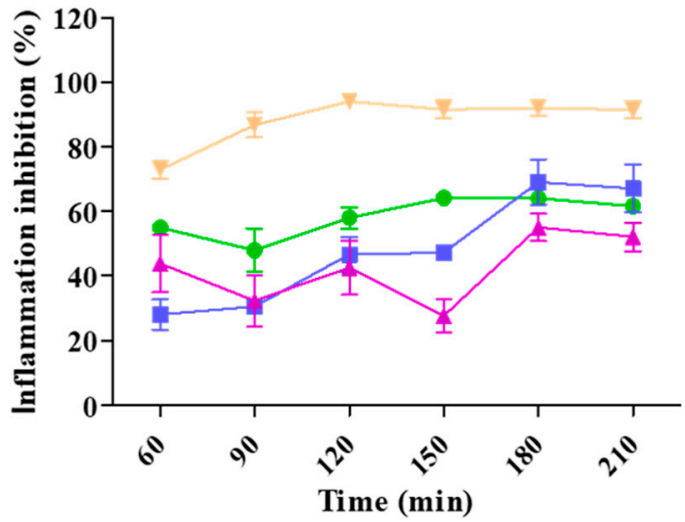

- Free Lico-A

$\rightarrow$ Lico-A PLGANPs

$\leftarrow$ Lic-A PLGA-PEG-Tet-1 NPs

$\rightarrow$ Lic-A PLGA-PEG-B6 NPs

Figure 7. Ocular anti-inflammatory results. (A) Ocular inflammation score. (B) Inhibition of inflammation (\%). Significant differences compared to the saline serum group: ${ }^{* *} p<0.01 ;{ }^{* * *} p<0.005$; **** $p<0.0001$.

Therefore, these results demonstrate that Lico-A could be used for ocular inflammation treatment and that surface functionalized NPs were able to decrease inflammation in a more prolonged manner than the free drug. Moreover, Lico-A PLGA-PEG-B6 NPs constitute the best strategy to administer Lico-A in ocular tissues, being able to reduce inflammation in a significantly effective manner. 


\section{Conclusions}

In the present manuscript, two formulations of Lico-A loaded peptide-functionalized biodegradable NPs were developed. Moreover, the DoE approach was confirmed to be a suitable method to optimize Lico-A PLGA NPs that showed a suitable short-term stability. In addition, PLGA surface was functionalized with PEG and custom-synthesized CPP obtaining two formulations: Lico-A PLGA-PEG-Tet1 NPs and Lico-A PLGA-PEG-B6 NPs. These formulations were characterized by obtaining an average size below $200 \mathrm{~nm}$ and a monodisperse system with highly positive surface charge. In addition, they demonstrated to provide a prolonged Lico-A release, slightly slower for Lico-A PLGA-PEG-Tet1 NPs. In addition, none of the formulations were irritants in vitro or in vivo. Furthermore, the ocular anti-inflammatory efficacy of Lico-A PLGA-PEG-B6 NPs was significantly superior compared to free Lico-A and Lico-A PLGA-PEG-Tet-1 NPs. Despite that, in all the cases the formulations developed showed significant anti-inflammatory effects against the control. However, Lico-A PLGA-PEG-B6 NPs were demonstrated to reduce inflammation in a highly effective manner constituting a promising system to be topically administered for ocular inflammation.

Supplementary Materials: The following are available online at https:/ / www.mdpi.com/article/10 .3390/ pharmaceutics14020285/s1, Figure S1: Chemical structure of CPPs. (A) Tet-1 peptide, (B) B6 peptide; Figure S2: Average size DoE analysis. (A) Pareto chart of average size, (B) surface response corresponding to average size obtained with $0.8 \%$ of Tween. Figure S3: Ocular tolerance Draize test results after $30 \mathrm{~min}$ of the product application. (A) Saline serum (control group), (B) Lico-A PLGA NPs, (C) Lic-A PLGA-PEG-Tet-1 NPs, (D) Lic-A PLGA-PEG-B6 NPs; Table S1. Peptide characterization by ESI-MS.

Author Contributions: Conceptualization, R.G.; M.J.G., M.E. (Marta Espina), M.E. (Miren Ettcheto), A.C. (Amanda Cano), I.H. and E.S.-L.; methodology, M.J.G., M.E. (Miren Ettcheto), A.C. (Amanda Cano); validation, R.G., E.S.-L.; formal analysis, M.E. (Marta Espina), I.H. and M.L.G.; investigation, R.G., A.C. (Antoni Camins); resources, A.C. (Antoni Camins); I.H., M.L.G.; writing-original draft preparation, R.G., E.S.-L., M.L.G., M.J.G.; writing—review and editing, E.S.-L.; M.J.G., I.H.; supervision, E.S.-L., M.J.G., A.C. (Antoni Camins), M.L.G.; funding acquisition, I.H., A.C. (Antoni Camins), M.L.G. All authors have read and agreed to the published version of the manuscript.

Funding: This research was funded by grant RTI2018-094120-B-I00 funded by MCIN/ AEI /10.13039/ 501100011033/ and by "ERDF A way of making Europe", by the Spanish Ministry of Science and Innovation and CIBER of neurodegenerative diseases (CIBERNED) (Grant CB06/05/2004 to AC and Instituto de Salud Carlos III).

Institutional Review Board Statement: The study was conducted according to the guidelines of the Declaration of Helsinki and approved by the Institutional Review Board (or Ethics Committee) of the University of Barcelona (protocol code 326/19 approved the 13 May 2021).

Data Availability Statement: Data is contained within the article or Supplementary Materials. The data presented of this study are available on request from the corresponding author.

Acknowledgments: The first author, RG, acknowledges the financial support of the Generalitat deCatalunya for the PhD scholarship FI-DGR EMC/2199/2017 (DOGC-7459-2017).

Conflicts of Interest: The authors declare no conflict of interest.

\section{References}

1. Sánchez-López, E.; Esteruelas, G.; Ortiz, A.; Espina, M.; Prat, J.; Muñoz, M.; Cano, A.; Calpena, A.C.; Ettcheto, M.; Camins, A.; et al. Dexibuprofen biodegradable nanoparticles: One step closer towards a better ocular interaction study. Nanomaterials 2020, 10, 720. [CrossRef] [PubMed]

2. Dennis, E.A.; Norris, P.C. Eicosanoid storm in infection and inflammation. Nat. Rev. Immunol. 2015, 15, 511-523. [CrossRef] [PubMed]

3. Yasir, M.; Goyal, A.; Bansal, P.; Sonthalia, S. Corticosteroid Adverse Effects; StatPearls Publishing: Treasure Island, FL, USA, 2021. 
4. $\quad$ De Freitas, K.S.; Squarisi, I.S.; Acésio, N.O.; Nicolella, H.D.; Ozelin, S.D.; Reis Santos de Melo, M.; Guissone, A.P.P.; Fernandes, G.; Silva, L.M.; da Silva Filho, A.A.; et al. Licochalcone A, a licorice flavonoid: Antioxidant, cytotoxic, genotoxic, and chemopreventive potential. J. Toxicol. Environ. Health Part A Curr. Issues 2020, 83, 673-686. [CrossRef] [PubMed]

5. Guo, I.M.W.; Liu, B.; Yin, Y.; Kan, X.; Gong, Q.; Li, Y.; Cao, Y.; Wang, J.; Xu, D.; Ma, H.; et al. Licochalcone A protects the blood milk barrier integrity and relieves the inflammatory response in LPS-Indued mastitis. Front. Immunol. 2019, 10, 1-14. [CrossRef] [PubMed]

6. Funakoshi-Tago, M.; Nakamura, K.; Tsuruya, R.; Hatanaka, M.; Mashino, T.; Sonoda, Y.; Kasahara, T. The fixed structure of Licochalcone A by $\alpha$, $\beta$-unsaturated ketone is necessary for anti-inflammatory activity through the inhibition of NF- $\mathrm{kB}$ activation. Int. Immunopharmacol. 2010, 10, 562-571. [CrossRef]

7. Wang, Z.; Xue, Y.; Zeng, Q.; Zhu, Z.; Wang, Y.; Wu, Y.; Shen, C.; Zhu, H.; Jiang, C.; Liu, L.; et al. Glycyrrhiza acid-Licochalcone A complexes for enhanced bioavailability and anti-melanogenic effect of Licochalcone A: Cellular uptake and in vitro experiments J. Drug Deliv. Sci. Technol. 2022, 68, 103037. [CrossRef]

8. Silva, L.M.; Marconato, D.G.; Nascimento Da Silva, M.P.; Barbosa Raposo, N.R.; De Faria Silva Facchini, G.; MacEdo, G.C.; Teixeira, F.D.S.; Da Silveira Salvadori, M.C.B.; De Faria Pinto, P.; De Moraes, J.; et al. Licochalcone A-loaded solid lipid nanoparticles improve antischistosomal activity in vitro and in vivo. Nanomedicine 2021, 16, 1641-1655. [CrossRef]

9. Sánchez-López, E.; Espina, M.; Doktorovova, S.; Souto, E.B.; García, M.L. Lipid nanoparticles (SLN, NLC): Overcoming the anatomical and physiological barriers of the eye-Part I-Barriers and determining factors in ocular delivery. Eur. J. Pharm. Biopharm. 2017, 110, 58-69. [CrossRef]

10. Sahu, T.; Ratre, Y.K.; Chauhan, S.; Bhaskar, L.V.K.S.; Nair, M.P.; Verma, H.K. Nanotechnology based drug delivery system: Current strategies and emerging therapeutic potential for medical science. J. Drug Deliv. Sci. Technol. 2021, 63, 102487. [CrossRef]

11. Gonzalez-pizarro, R.; Parrotta, G.; Vera, R.; Sánchez-lópez, E.; Galindo, R.; Kjeldsen, F.; Badia, J.; Baldoma, L.; Espina, M.; García, M.L. Ocular penetration of fluorometholone-loaded PEG-PLGA nanoparticles functionalized with cell-penetrating peptides. Nanomedicine 2019, 14, 3089-3104. [CrossRef]

12. Amadio, M.; Pascale, A.; Cupri, S.; Pignatello, R.; Osera, C.; D’Agata, V.; D’Amico, A.G.; Leggio, G.M.; Ruozi, B.; Govoni, S.; et al. Nanosystems based on siRNA silencing HuR expression counteract diabetic retinopathy in rat. Pharmacol. Res. 2016, 111, 713-720. [CrossRef] [PubMed]

13. Khiev, D.; Mohamed, Z.A.; Vichare, R.; Paulson, R.; Bhatia, S.; Mohapatra, S.; Lobo, G.P.; Valapala, M.; Kerur, N.; Passaglia, C.L.; et al. Emerging nano-formulations and nanomedicines applications for ocular drug delivery. Nanomaterials 2021, 11, 173. [CrossRef] [PubMed]

14. Shah, N. Nanocarriers: Drug Delivery System; Springer: Berlin/Heidelberg, Germany, 2021; ISBN 9789813344969.

15. Kumari, A.; Yadav, S.K.; Yadav, S.C. Biodegradable polymeric nanoparticles based drug delivery systems. Colloids Surf. B Biointerfaces 2010, 75, 1-18. [CrossRef] [PubMed]

16. Arafa, M.G.; Girgis, G.N.S.; El-Dahan, M.S. Chitosan-coated PLGA nanoparticles for enhanced ocular anti-inflammatory efficacy of atorvastatin calcium. Int. J. Nanomed. 2020, 15, 1335-1347. [CrossRef]

17. Sah, A.K.; Suresh, P.K.; Verma, V.K. PLGA nanoparticles for ocular delivery of loteprednol etabonate: A corneal penetration study. Artif. Cells Nanomed. Biotechnol. 2017, 45, 1156-1164. [CrossRef]

18. Mir, M.; Ahmed, N.; ur Rehman, A. Recent applications of PLGA based nanostructures in drug delivery. Colloids Surf. B Biointerfaces 2017, 159, 217-231. [CrossRef]

19. Vasconcelos, A.; Vega, E.; Pérez, Y.; Gómara, M.J.; García, M.L.; Haro, I. Conjugation of cell-penetrating peptides with poly(lacticco-glycolic acid)-polyethylene glycol nanoparticles improves ocular drug delivery. Int. J. Nanomed. 2015, 10, 609-631. [CrossRef]

20. Abrego, G.; Alvarado, H.; Souto, E.B.; Guevara, B.; Bellowa, L.H.; Parra, A.; Calpena, A.; Garcia, M.L. Biopharmaceutical profile of pranoprofen-loaded PLGA nanoparticles containing hydrogels for ocular administration. Eur. J. Pharm. Biopharm. 2015, 95, 261-270. [CrossRef]

21. Janagam, D.R.; Wu, L.; Lowe, T.L. Nanoparticles for drug delivery to the anterior segment of the eye. Adv. Drug Deliv. Rev. 2017, 122, 31-64. [CrossRef]

22. Sharma, S.; Parmar, A.; Kori, S.; Sandhir, R. PLGA-based nanoparticles: A new paradigm in biomedical applications. TrAC Trends Anal. Chem. 2016, 80, 30-40. [CrossRef]

23. Liu, Z.; Gao, X.; Kang, T.; Jiang, M.; Miao, D.; Gu, G.; Hu, Q. B6 Peptide-Modified PEG-PLA Nanoparticles for Enhanced Brain Delivery of Neuroprotective Peptide. Bioconjug. Chem. 2013, 24, 997-1007. [CrossRef] [PubMed]

24. Torchilin, V.P. Tat peptide-mediated intracellular delivery of pharmaceutical nanocarriers. Adv. Drug Deliv. Rev. 2008, 60, 548-558. [CrossRef] [PubMed]

25. Brooks, H.; Lebleu, B.; Vivès, E. Tat peptide-mediated cellular delivery: Back to basics. Adv. Drug Deliv. Rev. 2005, 57, 559-577. [CrossRef]

26. Rizzuti, M.; Nizzardo, M.; Zanetta, C.; Ramirez, A.; Corti, S. Therapeutic applications of the cell-penetrating HIV-1 Tat peptide. Drug Discov. Today 2015, 20, 76-85. [CrossRef] [PubMed]

27. Jones, S.W.; Christison, R.; Bundell, K.; Voyce, C.J.; Brockbank, S.M.V.; Newham, P.; Lindsay, M.A. Characterisation of cellpenetrating peptide-mediated peptide delivery. Br. J. Pharmacol. 2005, 145, 1093-1102. [CrossRef] [PubMed]

28. Guidotti, G.; Brambilla, L.; Rossi, D. Cell-Penetrating Peptides: From Basic Research to Clinics. Trends Pharmacol. Sci. 2017, 38, 406-424. [CrossRef] 
29. Mathew, A.; Fukuda, T.; Nagaoka, Y.; Hasumura, T.; Morimoto, H.; Yoshida, Y.; Maekawa, T.; Venugopal, K.; Kumar, D.S. Curcumin loaded-PLGA nanoparticles conjugated with Tet-1 peptide for potential use in Alzheimer's disease. PLoS ONE 2012, 7, e32616. [CrossRef]

30. Jia, T.T.; Sun, Z.G.; Lu, Y.; Gao, J.; Zou, H.; Xie, F.Y.; Zhang, G.Q.; Xu, H.; Sun, D.X.; Yu, Y.; et al. A dual brain-targeting curcumin-loaded polymersomes ameliorated cognitive dysfunction in intrahippocampal amyloid- $\beta 1-42$-injected mice. Int. J. Nanomed. 2016, 11, 3765-3775. [CrossRef]

31. Zhang, J.; Zhou, X.; Yu, Q.; Yang, L.; Sun, D.; Zhou, Y.; Liu, J. Epigallocatechin-3-gallate (EGCG)-stabilized selenium nanoparticles coated with Tet-1 peptide to reduce amyloid- $\beta$ aggregation and cytotoxicity. ACS Appl. Mater. Interfaces 2014, 6, 8475-8487. [CrossRef]

32. Blackburn, C.C.; Swank-Hill, P.; Schnaarb, R.L. Gangliosides Support Neural Retina Cell Adhesion. J. Biol. Chem. 1986, 261, 2873-2881. [CrossRef]

33. Yang, Z.; Zhao, Z.; Panjwani, N. Gangliosides of Migrating and Nonmigrating Corneal Epithelium in Organ and Cell Culture. Investig. Opthalmol. Vis. Sci. 1996, 37, 501-510.

34. Fan, S.; Zheng, Y.; Liu, X.; Fang, W.; Chena, X.; Liao, W.; Jing, X.; Lei, M.; Tao, E.; Ma, Q.; et al. Curcumin-loaded plga-peg nanoparticles conjugated with b6 peptide for potential use in alzheimer's disease. Drug Deliv. 2018, 25, 1044-1055. [CrossRef] [PubMed]

35. Daudouin, C.; Brignole, F.; Fredj-Reygrobeller, D.; Negre, F.; Boyle, J.; Gostoud, P. Transferrin Receptor Expression by Retinal Pigment Epithelial Cells in Proliferative Vitreoretinopathy. Investig. Ophthalmol. Vis. Sci. 1992, 33, 2822-2829.

36. Lauweryns, B.; Van Den Oord, J.J.; Missotten, L. The Transitional Zone Between Limbus and Peripheral Cornea. An lmmunohistochemical Study. Investig. Ophthalmol. Vis. Sci. 1993, 34, 1991-1999.

37. Tan, P.H.; King, W.J.; Chen, D.; Awad, H.M.; Mackett, M.; Lechler, R.I.; Frank, D.; Larkin, P.; George, A.J.T. Transferrin receptormediated gene transfer to the corneal endothelium. J. Muscle Res. Cell. Motil. 2001, 71, 552-560. [CrossRef]

38. Esteruelas, G.; Halbaut, L.; García-Torra, V.; Espina, M.; Cano, A.; Ettcheto, M.; Camins, A.; Souto, E.B.; Luisa García, M.; SánchezLópez, E. Development and optimization of Riluzole-loaded biodegradable nanoparticles incorporated in a mucoadhesive in situ gel for the posterior eye segment. Int. J. Pharm. 2021, 612, 121379. [CrossRef]

39. Fessi, H.; Puisieux, F.; Devissaguet, J.P.; Ammoury, N.; Benita, S. Nanocapsule formation by interfacial polymer deposition following solvent displacement. Int. J. Pharm. 1989, 55, R1-R4. [CrossRef]

40. Nadelmann, L.; Tjørnelund, J.; Christensen, E.; Hansen, S.H. High-performance liquid chromatographic determination of licochalcone A and its metabolites in biological fluids. J. Chromatogr. B Biomed. Appl. 1997, 695, 389-400. [CrossRef]

41. Xie, J.; Zhang, Y.; Wang, W. HPLC analysis of glycyrrhizin and licochalcone a in Glycyrrhiza inflata from Xinjiang (China). Chem. Nat. Compd. 2010, 46, 148-151. [CrossRef]

42. Lister, A.S. Validation of HPLC methods in pharmaceutical analysis. Sep. Sci. Technol. 2005, 6, 191-217. [CrossRef]

43. Sánchez-López, E.; Egea, M.A.; Cano, A.; Espina, M.; Calpena, A.C.C.; Ettcheto, M.; Camins, A.; Souto, E.B.B.; Silva, A.M.M.; García, M.L.L. PEGylated PLGA nanospheres optimized by design of experiments for ocular administration of dexibuprofenIn vitro, ex vivo and in vivo characterization. Colloids Surf. B Biointerfaces 2016, 145, 241-250. [CrossRef] [PubMed]

44. López-Machado, A.; Díaz-Garrido, N.; Cano, A.; Espina, M.; Badia, J.; Baldomà, L.; Calpena, A.C.; Souto, E.B.; García, M.L.; Sánchez-López, E. Development of Lactoferrin-Loaded Liposomes for the Management of Dry Eye Disease and Ocular Inflammation. Pharmaceutics 2021, 13, 1698. [CrossRef] [PubMed]

45. Jaradat, D.M.M. Thirteen decades of peptide synthesis: Key developments in solid phase peptide synthesis and amide bond formation utilized in peptide ligation. Amino Acids 2018, 50, 39-68. [CrossRef] [PubMed]

46. Sánchez-López, E.; Egea, M.A.; Davis, B.M.; Guo, L.; Espina, M.; Silva, A.M.; Calpena, A.C.; Souto, E.M.B.; Ravindran, N.; Ettcheto, M.; et al. Memantine-Loaded PEGylated Biodegradable Nanoparticles for the Treatment of Glaucoma. Small 2018, 14, 1-12. [CrossRef]

47. Andreani, T.; Miziara, L.; Lorenzón, E.N.; De Souza, A.L.R.; Kiill, C.P.; Fangueiro, J.F.; Garcia, M.L.; Gremião, P.D.; Silva, A.M.; Souto, E.B. Effect of mucoadhesive polymers on the in vitro performance of insulin-loaded silica nanoparticles: Interactions with mucin and biomembrane models. Eur. J. Pharm. Biopharm. 2015, 93, 118-126. [CrossRef]

48. Elmsmari, F.; González Sánchez, J.A.; Duran-Sindreu, F.; Belkadi, R.; Espina, M.; García, M.L.; Sánchez-López, E. Calcium hydroxide-loaded PLGA biodegradable nanoparticles as an intracanal medicament. Int. Endod. J. 2021, 54, 2086-2098. [CrossRef]

49. Warren, M.; Atkinson, K.; Steer, S. INVITTOX: The ERGATT/FRAME data bank of in vitro techniques in toxicology. Toxicol. Vitr. 1990, 4, 707-710. [CrossRef]

50. Gupta, H.; Aqil, M.; Khar, R.K.; Ali, A.; Bhatnagar, A.; Mittal, G. Biodegradable levofloxacin nanoparticles for sustained ocular drug delivery. J. Drug Target. 2011, 19, 409-417. [CrossRef]

51. Abrego, G.; Alvarado, H.L.; Egea, M.A.; Gonzalez-Mira, E.; Calpena, A.C.; Garcia, M.L. Design of nanosuspensions and freezedried PLGA nanoparticles as a novel approach for ophthalmic delivery of pranoprofen. J. Pharm. Sci. 2014, 103, 3153-3164. [CrossRef]

52. López-Machado, A.; Díaz, N.; Cano, A.; Espina, M.; Badía, J.; Baldomà, L.; Calpena, A.C.; Biancardi, M.; Souto, E.B.; García, M.L.; et al. Development of topical eye-drops of lactoferrin-loaded biodegradable nanoparticles for the treatment of anterior segment inflammatory processes. Int. J. Pharm. 2021, 609, 121188. [CrossRef] 
53. Vega, E.; Egea, M.; Valls, O.; Espina, M.; Garcia, M. Flurbiprofen loaded biodegradable nanoparticles for ophtalmic administration. J. Pharm. Sci. 2006, 95, 2393-2405. [CrossRef] [PubMed]

54. Vega, E.; Egea, M.A.; Calpena, A.C.; Espina, M.; García, M.L. Role of hydroxypropyl- $\beta$-cyclodextrin on freeze-dried and gammairradiated PLGA and PLGA-PEG diblock copolymer nanospheres for ophthalmic flurbiprofen delivery. Int. J. Nanomed. 2012, 7, 1357-1371. [CrossRef] [PubMed]

55. Folle, C.; Díaz-Garrido, N.; Sánchez-López, E.; Marqués, A.M.; Badia, J.; Baldomà, L.; Espina, M.; Calpena, A.C.; García, M.L. Surface-modified multifunctional thymol-loaded biodegradable nanoparticles for topical acne treatment. Pharmaceutics 2021, 13, 1501. [CrossRef] [PubMed]

56. Folle, C.; Marqués, A.M.; Díaz-Garrido, N.; Espina, M.; Sánchez-López, E.; Badia, J.; Baldoma, L.; Calpena, A.C.; García, M.L. Thymol-loaded PLGA nanoparticles: An efficient approach for acne treatment. J. Nanobiotechnol. 2021, 19, 359. [CrossRef] [PubMed]

57. Sahoo, S.K.; Dilnawaz, F.; Krishnakumar, S. Nanotechnology in ocular drug delivery. Drug Discov. Today 2008, 13, 144-151. [CrossRef]

58. Song, X.; Zhao, Y.; Hou, S.; Xu, F.; Zhao, R.; He, J.; Cai, Z.; Li, Y.; Chen, Q. Dual agents loaded PLGA nanoparticles: Systematic study of particle size and drug entrapment efficiency. Eur. J. Pharm. Biopharm. 2008, 69, 445-453. [CrossRef]

59. Liu, P.; Chen, N.; Yan, L.; Gao, F.; Ji, D.; Zhang, S.; Zhang, L.; Li, Y.; Xiao, Y. Preparation, characterisation and in vitro and in vivo evaluation of CD44-targeted chondroitin sulphate-conjugated doxorubicin PLGA nanoparticles. Carbohydr. Polym. 2019, 213, 17-26. [CrossRef]

60. Espinoza, L.C.; Silva-Abreu, M.; Clares, B.; Rodríguez-Lagunas, M.J.; Halbaut, L.; Cañas, M.A.; Calpena, A.C. Formulation strategies to improve nose-to-brain delivery of donepezil. Pharmaceutics 2019, 11, 64. [CrossRef]

61. Sánchez-López, E.; Ettcheto, M.; Egea, M.A.; Espina, M.; Calpena, A.C.; Folch, J.; Camins, A.; García, M.L. New potential strategies for Alzheimer's disease prevention: Pegylated biodegradable dexibuprofen nanospheres administration to APPswe/PS1dE9. Nanomed. Nanotechnol. Biol. Med. 2017, 13, 1171-1182. [CrossRef]

62. Espinoza, L.C.; Vera-García, R.; Silva-Abreu, M.; Domènech, Ò.; Badia, J.; Rodríguez-Lagunas, M.J.; Clares, B.; Calpena, A.C Topical pioglitazone nanoformulation for the treatment of atopic dermatitis: Design, characterization and efficacy in hairless mouse model. Pharmaceutics 2020, 12, 255. [CrossRef]

63. Mohsen, A.M. Cationic Polymeric Nanoparticles for Improved Ocular Delivery and Antimycotic Activity of Terconazole. J. Pharm. Sci. 2021, 111, 458-468. [CrossRef] [PubMed]

64. Jia, T.; Qiao, J.; Guan, D.; Chen, T. Anti-Inflammatory Effects of Licochalcone A on IL-1ß-Stimulated Human Osteoarthritis Chondrocytes. Inflammation 2017, 40, 1894-1902. [CrossRef] [PubMed]

65. Phan, H.T.L.; Kim, H.J.; Jo, S.; Kim, W.K.; Namkung, W.; Nam, J.H. Anti-inflammatory effect of licochalcone a via regulation of ORAI1 and K+ channels in T-Lymphocytes. Int. J. Mol. Sci. 2021, 22, 847. [CrossRef] [PubMed]

66. Salatin, S.; Maleki Dizaj, S.; Yari Khosroushahi, A. Effect of the surface modification, size, and shape on cellular uptake of nanoparticles. Cell Biol. Int. 2015, 39, 881-890. [CrossRef] 